Article

\title{
Ammonium Polyphosphate Intercalated Layered Double Hydroxide and Zinc Borate as Highly Efficient Flame Retardant Nanofillers for Polypropylene
}

\author{
Yanshan Gao ${ }^{1}{ }^{\mathbb{D}}$, Qiang Wang ${ }^{1, *}$ and Weiran Lin ${ }^{2, *}$ \\ 1 Beijing Key Lab for Source Control Technology of Water Pollution, Beijing Forestry University, \\ 35 Qinghua East Road, Haidian District, Beijing 100083, China; yanshan_gao@bjfu.edu.cn \\ 2 Beijing Research Institute of Chemical Industry, SINOPEC, Beijing 100013, China \\ * Correspondence: qiangwang@bjfu.edu.cn (Q.W.); linwr.bjhy@sinopec.com (W.L.); \\ Tel.: +86-1369-913-0626 (Q.W.); +86-1381-027-0882 (W.L.)
}

Received: 28 August 2018; Accepted: 5 October 2018; Published: 9 October 2018

\begin{abstract}
We found in our previous study that layered double hydroxides (LDHs) which undergo aqueous miscible organic solvent treatment (AMOST) can tune the hydrophobicity surface of LDHs to be hydrophobic, and then the solvent mixing method can be used to prepare polymer/LDH nanocomposites. However, flame retardant property is not very high if LDHs are only used. In this present work, ammonium polyphosphate (APP) intercalated LDHs and zinc borate (ZB) was incorporated into a polypropylene (PP) matrix using the solvent mixing method. The structures, morphologies, and performance of the composites were characterized carefully. The peak heat release rate (PHRR) reduction of PP containing 10 and $20 \mathrm{wt} \%$ APP-LDH reached $27 \%$ and $55 \%$, respectively, which increased up to $63 \%$ compared with $\mathrm{PP} / \mathrm{CO}_{3}-\mathrm{LDH}$. After incorporating $2 \mathrm{wt} \%$ $\mathrm{ZB}$ in the PP/APP-LDH system, the flame retardant property was further improved. Polypropylene composites with $20 \mathrm{wt} \%$ APP-LDH and $2 \mathrm{wt} \%$ ZB showed a 58\% PHRR reduction. In addition, thermogravimetric analyzer (TGA) results indicated that the addition of APP-LDH and ZB improved the temperature at $50 \%$ weight loss $\left(T_{50 \%}\right)$ and the char formation of the materials significantly.
\end{abstract}

Keywords: flame retardancy; thermal stability; polypropylene; APP-LDH; zinc borate

\section{Introduction}

Polypropylenes (PPs) are involved in a wide range of applications, such as the automotive, home appliance, and construction industries, etc., due to their ease of processing, excellent mechanical, electrical, chemical resistance, and non-toxicity [1]. However, most polymer materials, including PPs, are mainly composed of $\mathrm{C}, \mathrm{H}$, and $\mathrm{O}$ elements, which are easy to burn and generate smoke and toxic, and harmful gases during their combustion, which is a serious threat to both human bodies and the environment. The increased use of these polymer materials has resulted in a growing awareness of flammability problems. Therefore, the development of suitable flame retardant additives for PPs to delay the production and spreading of flames has attracted much attention [2].

Among the variety of flame retardants, layered double hydroxides (LDHs) have been regarded as effective flame retardants as well as electrocatalysts [3], $\mathrm{CO}_{2}$ adsorbents [4], and supercapacitors [5], due to their unique layered structures [6-9]. Besides, LDHs can improve the thermal stability of polymers as well; a small amount of LDHs can increased the thermostability significantly. However, similar to general inorganic flame retardants, one of the severe problems of LDHs is that their high loading, generally 40 60 wt \% can achieve a good degree of flame retardancy when only LDHs are used $[10,11]$, which usually results in poor mechanical and thermal properties of the materials. Hence, 
in order to overcome this problem, LDHs together with other synergistic flame retardant additives is recommended, such as magnesium hydroxide [12], phosphorus-containing compounds [13,14], carbon-based materials [15], borate-containing materials [16], $\mathrm{Ni}(\mathrm{OH})_{2}$ [17], or intumescent flame retardants [18], and so on. Among these, ammonium polyphosphate (APP) shows excellent flame retardant performance because of its lower loadings and cost, as well as good processability [2]. In addition, APP is halogen free, so it will not generate harmful gases during its use, which makes environmentally friendly compared with halogen-containing additives [19]. Some researchers have investigated the synergistic effect between LDH and APP; all composites can reach a UL-94 V-0 rating when incorporating APP in polymer/LDH systems [20-23]. However, in these studies, APP and LDHs particles were just physically mixed together, and we wondered if APP intercalated LDH (APP-LDHs) could further improve the flame retardant performance of polymers. Therefore, APP-LDHs were synthesized first and the flame retardant and thermal stability behaviors of PP / APP-LDH composites were investigated carefully in this study.

In addition, it is reported that zinc borates (ZBs) combined with LDH can function as a synergistic additive promoting formation of a char residue, as well as acting as a protective layer on the surface of polymers [24,25]. Zinc borates with different chemical formulas are usually used as flame retardant additives [26,27]. In our previous study [28], we demonstrated that a good dispersion of a flame retardant additive in the polymer matrix is also important. However, the ZB particles cannot always be dispersed well in polymers. In this contribution, we report the synthesis of one kind of $\mathrm{Zn}_{3} \mathrm{~B}_{10} \mathrm{O}_{18} \cdot 14 \mathrm{H}_{2} \mathrm{O}$ morphology-a combination of rods and particles by solution method—and turn its surface hydrophobic so that it can be uniformly dispersed in the polymer matrix.

In this work, we take advantage of the layered structure of LDHs and the superior flame retardant performance of APP, synthesizing APP intercalated LDHs and investigate both the fire resistance and thermal stability of APP-LDH. On the basis of this, the synergistic effect of LDHs and zinc borate is considered as well.

\section{Materials and Methods}

\subsection{Materials}

Materials were procured as follows: polypropylene (average molecular weight ca. 300,000, The Dow Chemical Company, Midland, MI, USA), $\mathrm{Mg}\left(\mathrm{NO}_{3}\right)_{2} \cdot 6 \mathrm{H}_{2} \mathrm{O}$ (AR, Sinopharm Chemical Reagent Co., Ltd., Shanghai, China), $\mathrm{Al}\left(\mathrm{NO}_{3}\right)_{3} \cdot 9 \mathrm{H}_{2} \mathrm{O}$ (AR, Sinopharm Chemical Reagent Co., Ltd., Shanghai, China), APP (Adamas-beta Company, Basel, Switzerland), $\mathrm{Na}_{2} \mathrm{~B}_{4} \mathrm{O}_{7} \cdot 10 \mathrm{H}_{2} \mathrm{O}$ (AR, Sinopharm Chemical Reagent Co., Ltd., Shanghai, China), $\mathrm{ZnSO}_{4} \cdot 7 \mathrm{H}_{2} \mathrm{O}$ (AR, Sinopharm Chemical Reagent Co., Ltd., Shanghai, China), $\mathrm{H}_{3} \mathrm{BO}_{3}$ (AR, Sinopharm Chemical Reagent Co., Ltd., Shanghai, China), acetone (AR, Beijing Chemical Works, Beijing, China), sodium hydroxide (AR, Sinopharm Chemical Reagent Co., Ltd., Shanghai, China), xylene (AR, Beijing Chemical Works, Beijing, China), and hexane (AR, Sinopharm Chemical Reagent Co., Ltd., Shanghai, China).

\subsection{Synthesis of Aqueous Miscible Organic (AMO)-LDH}

$\mathrm{Mg}_{3} \mathrm{Al}$-APP LDH was synthesized using a traditional hydrothermal approach. A solution containing $9.60 \mathrm{~g} \mathrm{Mg}\left(\mathrm{NO}_{3}\right)_{2} \cdot 6 \mathrm{H}_{2} \mathrm{O}$ and $4.70 \mathrm{~g} \mathrm{Al}\left(\mathrm{NO}_{3}\right)_{3} \cdot 9 \mathrm{H}_{2} \mathrm{O}$ in $50 \mathrm{~mL}$ deionized water and $\mathrm{NaOH}$ (4 M) was added into an APP solution ( $25 \mathrm{~g}$ APP in $50 \mathrm{~mL}$ deionized water), the $\mathrm{pH}$ of the system was $\sim 10$. The obtained mixture slurry was sealed in an autoclave and reacted at $100{ }^{\circ} \mathrm{C}$ for 24 h. After the reaction, the slurry was centrifuged and washed with water until its $\mathrm{pH}$ was neutral condition. Then it was treated with acetone to tune the LDH surface from hydrophilic to hydrophobic. For the PP / APP-LDH nanocomposites, the resultant AMO-LDH was directly used without drying. $\mathrm{Mg}_{3} \mathrm{Al}-\mathrm{CO}_{3} \mathrm{LDH}$ was synthesized similarly. 


\subsection{Synthesis of Zinc Borate}

Zinc Borate with uniform morphology was prepared at $90{ }^{\circ} \mathrm{C}$ using $\mathrm{Na}_{2} \mathrm{~B}_{4} \mathrm{O}_{7} \cdot 10 \mathrm{H}_{2} \mathrm{O}$, $\mathrm{ZnSO}_{4} \cdot 7 \mathrm{H}_{2} \mathrm{O}$ and $\mathrm{H}_{3} \mathrm{BO}_{3}$ as raw materials. In detail, the mixture of $19.07 \mathrm{~g}$ of $\mathrm{Na}_{2} \mathrm{~B}_{4} \mathrm{O}_{7} \cdot 10 \mathrm{H}_{2} \mathrm{O}$, $6.18 \mathrm{~g}$ of $\mathrm{H}_{3} \mathrm{BO}_{3}$, and $50 \mathrm{~mL}$ of deionized water was stirred at $70{ }^{\circ} \mathrm{C}$. Then $14.38 \mathrm{~g}$ of $\mathrm{ZnSO}_{4} \cdot 7 \mathrm{H}_{2} \mathrm{O}$ was added into the mixture solution and further stirred for $8 \mathrm{~h}$ at $90^{\circ} \mathrm{C}$. The obtained white precipitates were similarly treated with LDH.

\subsection{Preparation of PP/APP-LDH and PP/APP-LDH/ZB Nanocomposites}

The solvent mixing method was used to synthesize PP/APP-LDH nanocomposites. In detail, a certain amount of PP and APP-LDH (total amount $5 \mathrm{~g}$, the LDH loading in PP was 10 and $20 \mathrm{wt} \%$, respectively) was added into $100 \mathrm{~mL}$ xylene. Refluxing at $\sim 140{ }^{\circ} \mathrm{C}$ for at least $2 \mathrm{~h}$ to obtain dissolved PP solution with highly dispersion of LDH particles. Then the hot solution was poured into $100 \mathrm{~mL}$ hexane. After being filtered and dried, the PP/APP-LDH nanocomposites were obtained. Polypropylene/APP-LDH/ZB nanocomposites were prepared in the same way.

\subsection{Characterization of Samples}

X-ray diffraction (XRD) results were performed on a Shimadzu XRD-7000S instrument (Cu K $\alpha$ radiation, the accelerating voltage $40 \mathrm{kV}$, current $30 \mathrm{~mA}(\lambda=1.542 \AA), 2 \theta$ degree from $2^{\circ}$ to $70^{\circ}$, scanning rate $5^{\circ} \mathrm{min}^{-1}$, Kyoto, Japan). Fourier Transform Infrared Spectroscopy (FT-IR) spectra were recorded on a Bruker VERTEX 70 FT-IR spectrophotometer $\left(400-4000 \mathrm{~cm}^{-1}, 100\right.$ scans with a resolution of $4 \mathrm{~cm}^{-1}$, Munich, Germany). Scanning electron microscopy-energy dispersive spectrometer (SEM-EDS) analyses were recorded on a Hitachi SU-8010 machine (accelerating voltage of $5.0 \mathrm{kV}$, Tokyo, Japan). ${ }^{27} \mathrm{Al}$ NMR analysis was performed on a Bruker Advance 500 spectrometer (Munich, Germany) at a resonance frequency of $130.44 \mathrm{MHz}$ with a $4 \mathrm{~mm}$ triple-resonance magic angle spinning (MAS) probe; the sample spinning rate was $10 \mathrm{kHz}$. Differential scanning calorimetry (DSC) analyses were performed using a Shimadzu TA-60WS instrument (Kyoto, Japan), heating rate was $10{ }^{\circ} \mathrm{C} \cdot \mathrm{min}^{-1}$, nitrogen flow rate was ca. $50 \mathrm{~mL} \cdot \mathrm{min}^{-1}$.

\subsection{Thermal Stability and Flammability Properties}

The thermal stabilities were evaluated using a TGA Q50 machine (TA Instruments, New Castle, $\mathrm{DE}$, USA), the heating rate was $10^{\circ} \mathrm{C} \cdot \mathrm{min}^{-1}$, and the air flow rate was $20 \mathrm{~mL} \mathrm{~min}{ }^{-1}$. Experiments were undertaken from 20 to $600^{\circ} \mathrm{C}$. The flammability performance was investigated using a microscale combustion calorimeter (MCC-2, Govmark, Farmingdale, NY, USA), with sample mass of $5 \mathrm{mg}$ and heating rate of $1{ }^{\circ} \mathrm{C} \mathrm{s}^{-1}$, and nitrogen flowing of $80 \mathrm{~cm}^{3} \mathrm{~min}^{-1}$. Experiments were undertaken from room temperature to $700{ }^{\circ} \mathrm{C}$.

\section{Results}

\subsection{Characterization of LDHs and Zinc Borate}

Figure 1a presents the XRD patterns of APP, $\mathrm{Mg}_{3} \mathrm{Al}-\mathrm{CO}_{3} \mathrm{LDH}$, and $\mathrm{Mg}_{3} \mathrm{Al}-\mathrm{APP} \mathrm{LDH} . \mathrm{Mg}_{3} \mathrm{Al}-\mathrm{CO}_{3}$ LDH exhibited the typical reflections of LDHs; the sharp basal reflection (00l) harmonics at relatively low $2 \theta$ angles indicated a well-crystallized structure of LDH. The characteristic Bragg reflection of (003) was observed at $11.36^{\circ}$, corresponding to a $0.78 \mathrm{~nm}$ interlayer spacing. For APP-LDH, the (003) diffraction peak moved to a lower angle $\left(2 \theta=9.34^{\circ}\right)$, with an interlayer distance of $0.93 \mathrm{~nm}$, which can be attributed to the intercalation of the relatively larger molecule of APP in the LDH interlayers. Nevertheless, Bragg reflections with low intensity were observed in $\mathrm{Mg}_{3} \mathrm{Al}-\mathrm{APP} \mathrm{LDH}$. This is perhaps because the APP-LDH become more amorphous, and thus there is insufficient coherence along the platelet stacking axis (c-axis) to observe any high intensity (00l) Bragg reflection [29]. 
In order to have a better understanding of the LDH structure, ${ }^{27} \mathrm{Al}$ solid state NMR analysis was performed, as shown in Figure 1c. The NMR spectra of LDH nanoparticles exhibited a single resonance near 9.4 ppm, which can be assigned to octahedrally coordinated $\mathrm{Al}$ [30]. The result confirmed that the LDH structure was formed by metals coordinated to six hydroxyl groups with octahedral geometry.
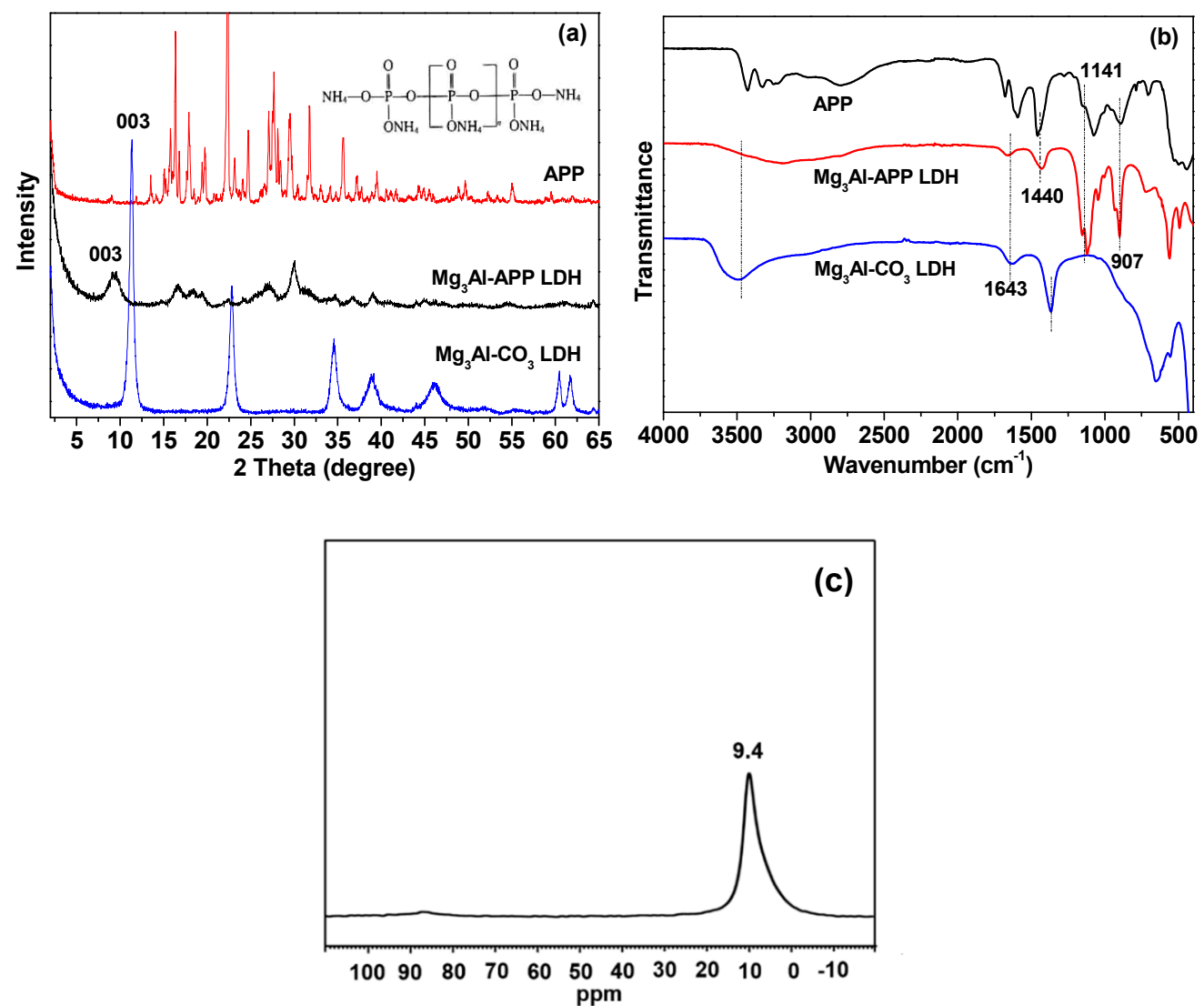

Figure 1. (a) X-ray diffraction (XRD) patterns of $\mathrm{APP}, \mathrm{Mg}_{3} \mathrm{Al}-\mathrm{CO}_{3} \mathrm{LDH}$, and $\mathrm{Mg}_{3} \mathrm{Al}-\mathrm{APP} \mathrm{LDH}$; (b) FT-IR spectrum of $\mathrm{APP}, \mathrm{Mg}_{3} \mathrm{Al}-\mathrm{CO}_{3} \mathrm{LDH}$, and $\mathrm{Mg}_{3} \mathrm{Al}-\mathrm{APP} \mathrm{LDH}$; and (c) ${ }^{27} \mathrm{Al}$ solid NMR spectra of LDH.

Fourier transform infrared spectroscopy spectra of APP, $\mathrm{Mg}_{3} \mathrm{Al}_{-} \mathrm{CO}_{3} \mathrm{LDH}$, and $\mathrm{Mg}_{3} \mathrm{Al}-\mathrm{APP} \mathrm{LDH}$ are displayed in Figure $1 \mathrm{~b}$. A broad band around $3400-3500 \mathrm{~cm}^{-1}$ was due to the $\mathrm{OH}$ stretching of water molecules, and the bending vibration around $1643 \mathrm{~cm}^{-1}$ was also due to the interlayer of $\mathrm{H}_{2} \mathrm{O}$. The adsorption peak at $562 \mathrm{~cm}^{-1}$ belongs to $\mathrm{MO}, \mathrm{OMO}$, and MOM lattice vibrations (M represents $\mathrm{Mg}$ and $\mathrm{Al}$ ). The band at $1365 \mathrm{~cm}^{-1}$ is attributed to the interlayer of $\mathrm{CO}^{2-}$. Besides, the bands at 1141,907 , and $1440 \mathrm{~cm}^{-1}$ are attributed to the vibrations of $\mathrm{P}-\mathrm{O}$ and $\mathrm{N}-\mathrm{H}$ group, respectively, demonstrating the presence of phosphate in the obtained APP-LDH nanoparticles [29]. The spectra results suggest a successful intercalation of APP molecules into the interlayers of LDH and that they were not decomposed.

Figure 2 presents the SEM-EDS images of $\mathrm{Mg}_{3} \mathrm{Al}-\mathrm{CO}_{3} \mathrm{LDH}$ and $\mathrm{Mg}_{3} \mathrm{Al}-\mathrm{APP} \mathrm{LDH}$. Both LDHs have formed plate-like nanoparticles with plate-like shapes with a diameter around 100 300 nm, according to the SEM images, and normal distribution of particles, which is consistent with previous studies [9,31]. However, the particle diameters of APP intercalated with LDH were a little larger than the carbonate intercalated with LDH. The EDS mapping indicates the presence of $\mathrm{P}$ elements in the $\mathrm{Mg}_{3} \mathrm{Al}-\mathrm{APP} \mathrm{LDH}$, whereas almost no P elements were found in the $\mathrm{Mg}_{3} \mathrm{Al}-\mathrm{CO}_{3} \mathrm{LDH}$, further confirming that APP molecule existed in the LDH interlayers. The EDS results are in agreement with both XRD and FT-IR results. 


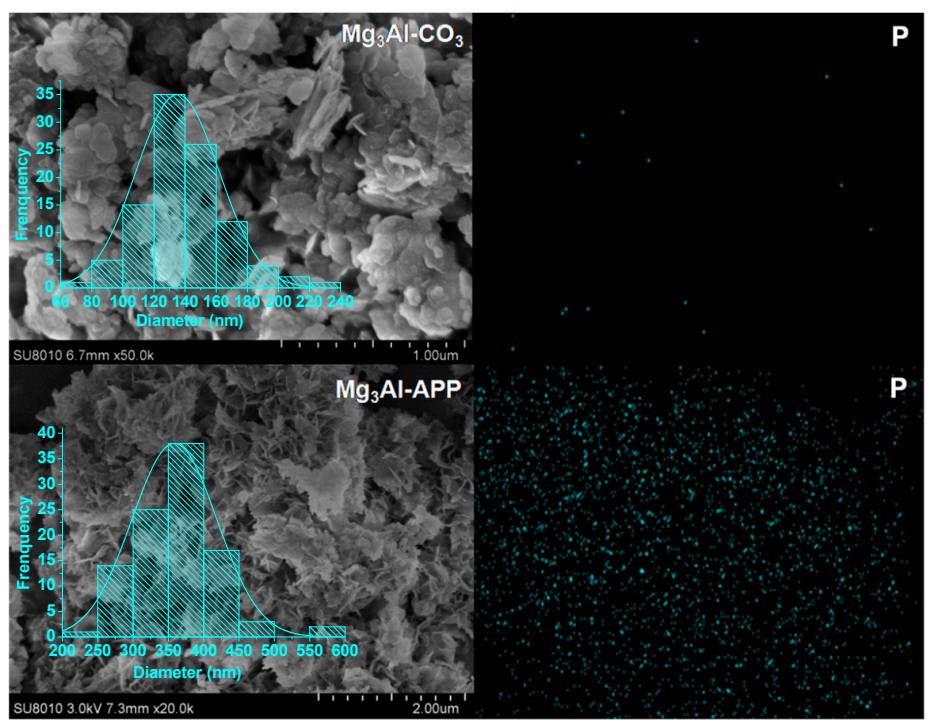

Figure 2. SEM images of $\mathrm{Mg}_{3} \mathrm{Al}-\mathrm{CO}_{3}$ and $\mathrm{Mg}_{3} \mathrm{Al}-\mathrm{APP} \mathrm{LDH}$ and corresponding EDS mapping of phosphorus.

Figure 3a represents the $X R D$ patterns of the $Z B$. The $X R D$ results were consistent with the pure phase of $\mathrm{Zn}_{3} \mathrm{~B}_{10} \mathrm{O}_{18} \cdot 14 \mathrm{H}_{2} \mathrm{O}$ (File No. 32-1461), indicating that the $\mathrm{ZB}$ was synthesized successfully. The FT-IR spectra of ZB exhibited some bands and can be assigned as follows (Figure 3c,d) [32-34]. The band at $3300-3400 \mathrm{~cm}^{-1}$ is the $\mathrm{O}-\mathrm{H}$ stretching while the adsorption peaks at $2655 \mathrm{~cm}^{-1}$ is because of hydrogen band. The band at $1644 \mathrm{~cm}^{-1}$ can be attributed to the $\mathrm{H}-\mathrm{O}-\mathrm{H}$ from crystalline water. The characteristic bands at 1351 and $923 \mathrm{~cm}^{-1}$ are the asymmetric and symmetric stretching of $\mathrm{B}_{(3)}-\mathrm{O}$ (means three coordinate boron). The peak at $1213 \mathrm{~cm}^{-1}$ represent the bending of $\mathrm{B}-\mathrm{O}-\mathrm{H}$. The peaks at $1113 \mathrm{~cm}^{-1}, 833 \mathrm{~cm}^{-1}$, and $759 \mathrm{~cm}^{-1}$ are the stretching of $\mathrm{B}_{(4)}-\mathrm{O}$ (means four coordinate boron). The band at $639 \mathrm{~cm}^{-1}, 519 \mathrm{~cm}^{-1}$, and $578 \mathrm{~cm}^{-1}$ are derived from $\mathrm{B}_{(3)}-\mathrm{O}$. The peak at $455 \mathrm{~cm}^{-1}$ is due to the $\mathrm{B}_{(4)}-\mathrm{O}$ bending. Fourier transform infrared spectroscopy results further confirmed the successful synthesis of ZB. As seen in Figure 3b, the morphologies of the materials are combination of rods (about $1-3 \times 10 \mu \mathrm{m}$ ) and particles (diameter less than $1 \mu \mathrm{m}$ ).
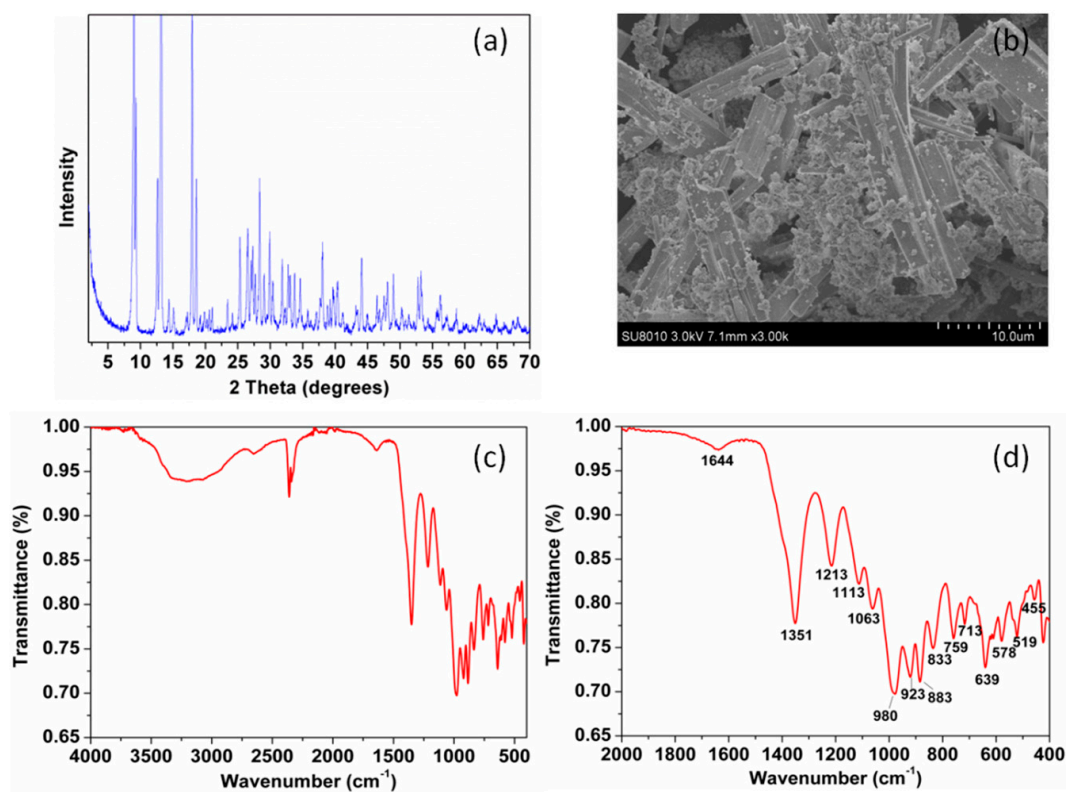

Figure 3. (a) XRD patterns, (b) SEM images, (c) FT-IR spectrum, and (d) enlarged FT-IR spectrum of zinc borate. 


\subsection{Characterization of $P P / A P P-L D H$ and $P P / A P P-L D H / Z B$ Nanocomposites}

Figure 4 presents the XRD results of pure PP and PP nanocomposites containing LDH and ZB. Pure PP has a semi-crystalline structure with several main reflections at $14-23^{\circ}$. For both $\mathrm{PP} / 10$ APP-LDH and PP/20 APP-LDH nanocomposites, a reflection at $2 \theta=9.3^{\circ}$ can be found in Figure $4 \mathrm{a}$, which correspond to the (003) reflection of APP-LDH. This results indicate that the dispersed LDH retains a layer structure after solvent mixing with PP. The (003) peak also increased with the increasing of LDH addition amount. However, when the PP/LDH nanocomposites were prepared with 2-6 wt \% ZB (Figure $4 b$ ), only the typical peaks of PP and LDH can be seen, suggesting that the ZB was dispersed in the PP matrix amorphously.
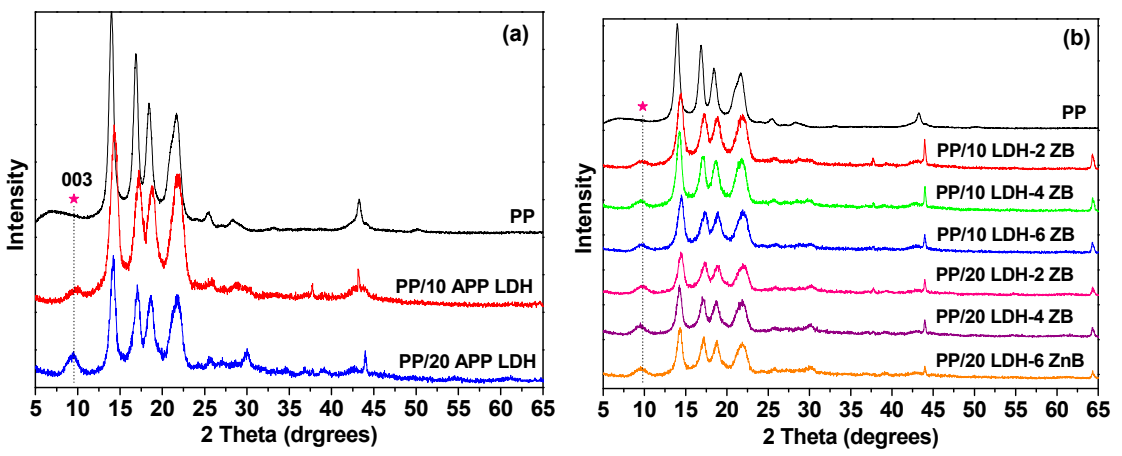

Figure 4. XRD patterns of PP, (a) PP/APP-LDH, and (b) PP/APP-LDH/ZB nanocomposites.

Scanning electron micrographs of the samples are shown in Figure 5. Pure PP shows a spherical morphology with a very smooth surface (Figure 5a). After adding 10-20 wt \% LDH, the PP/LDH nanocomposites became rough, especially with $20 \mathrm{wt} \% \mathrm{LDH}$, there were imperfections in the spherical structure (Figure $5 \mathrm{c}$ ). However, nearly no LDH nanoparticles can be seen on PP surface, indicating that the LDH nanoparticles can be excellently dispersed in PP matrix by acetone modification. The PP $/ 2 \%$ $\mathrm{ZB}$ nanocomposites were very similar with $\mathrm{PP}$ in terms of their morphologies and sizes. When combining $10 \%$ LDHs with $2 \% \mathrm{ZB}$ together, both $\mathrm{LDH}$ particles and $\mathrm{ZB}$ can rarely be observed on the surface of the spherical-like PP; however, the spherical structure was destroyed when the LDH increased to $20 \%$, this was due to the high loading of LDH.

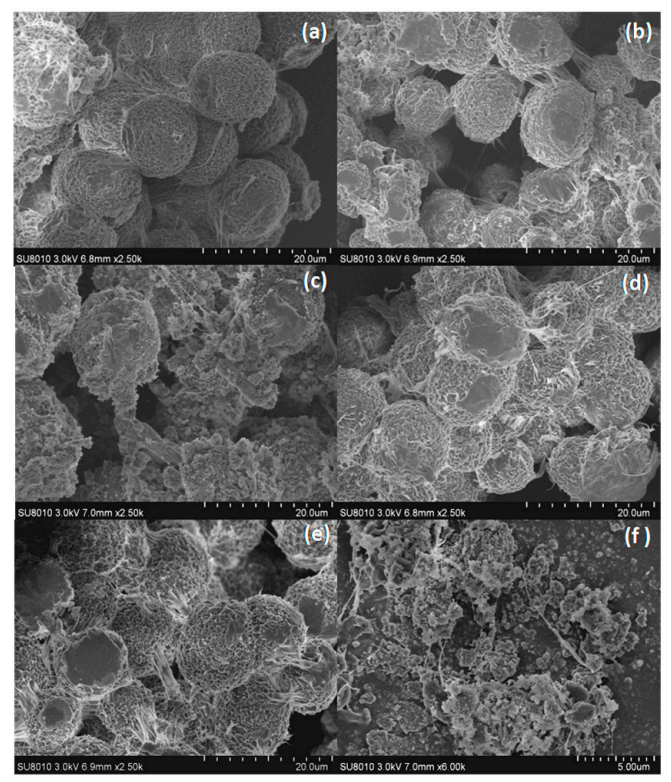

Figure 5. SEM results of (a) PP, (b) PP $/ 10 \%$ APP-LDH, (c) PP $/ 20 \%$ APP-LDH, (d) PP $/ 2 \%$ ZB, (e) $\mathrm{PP} / 10 \%$ APP-LDH $/ 2 \%$ ZB, and (f) PP $/ 20 \%$ APP-LDH $/ 2 \%$ ZB nanocomposites. 


\subsection{Thermal and Flammable Properties of PP-Based Nanocomposites}

In order to obtain a composite with perfect properties, it was necessary to understand the thermal decomposition [35,36]. The typical thermogravimetric analyzer (TGA) curves of APP-LDH and PP/LDH nanocomposites are presented in Figure 6. The relative thermal stability of the samples was usually evaluated by the temperature at $10 \%$ weight loss $\left(T_{10 \%}\right)$, the temperature at $50 \%$ weight loss $\left(T_{50 \%}\right)$, and the char residual percentage at $600{ }^{\circ} \mathrm{C}$, as listed in Table 1 . In contrast to pure $\mathrm{PP}$, the $T_{10 \%}$ of PP $/ 10 \%$ APP-LDH nanocomposites increased by $30{ }^{\circ} \mathrm{C}$; however, the PP nanocomposites with $20 \%$ APP-LDH exhibited a reduction in $T_{10 \%}$, which was probably attributed to the decomposition of the LDH particles, as shown in Figure 6a. Besides, when the loading of LDH increased, the addition of APP-LDH promoted and catalyzed the degradation of PP to a small extent in the initial stage, thus the $T_{10 \%}$ decreased. The char layer catalyzed by APP-LDH slowed down the heat release rate upon the ignition of $\mathrm{PP}$, and thus protected the inside polymer matrix from being degraded by the flame. As to the $T_{50} \%$, both PP nanocomposites increased no matter with $10 \%$ or $20 \%$ LDH loading. However, the $T_{50 \%}$ of $\mathrm{PP} / 10 \%$ APP-LDH increased by $52{ }^{\circ} \mathrm{C}$, while it only increased $7{ }^{\circ} \mathrm{C}$ for $\mathrm{PP} / 20 \%$ APP-LDH (Figure $6 \mathrm{~b}$ ). This result indicated that addition of LDH particles could enhance the thermal stability of polymers significantly, but it would decrease with a high loading. Therefore, it is necessary to reduce the additives loading in polymers under the premise of highly efficient flame retardant performance. In addition, only $0.7 \mathrm{wt} \%$ char residue was obtained for pure PP. The addition of LDHs also improved the char yield to 7.0 and $24.1 \mathrm{wt} \%$ from $0.7 \mathrm{wt} \%$ for PP $/ 10 \%$ APP-LDH and PP $/ 20 \%$ APP-LDH, respectively.
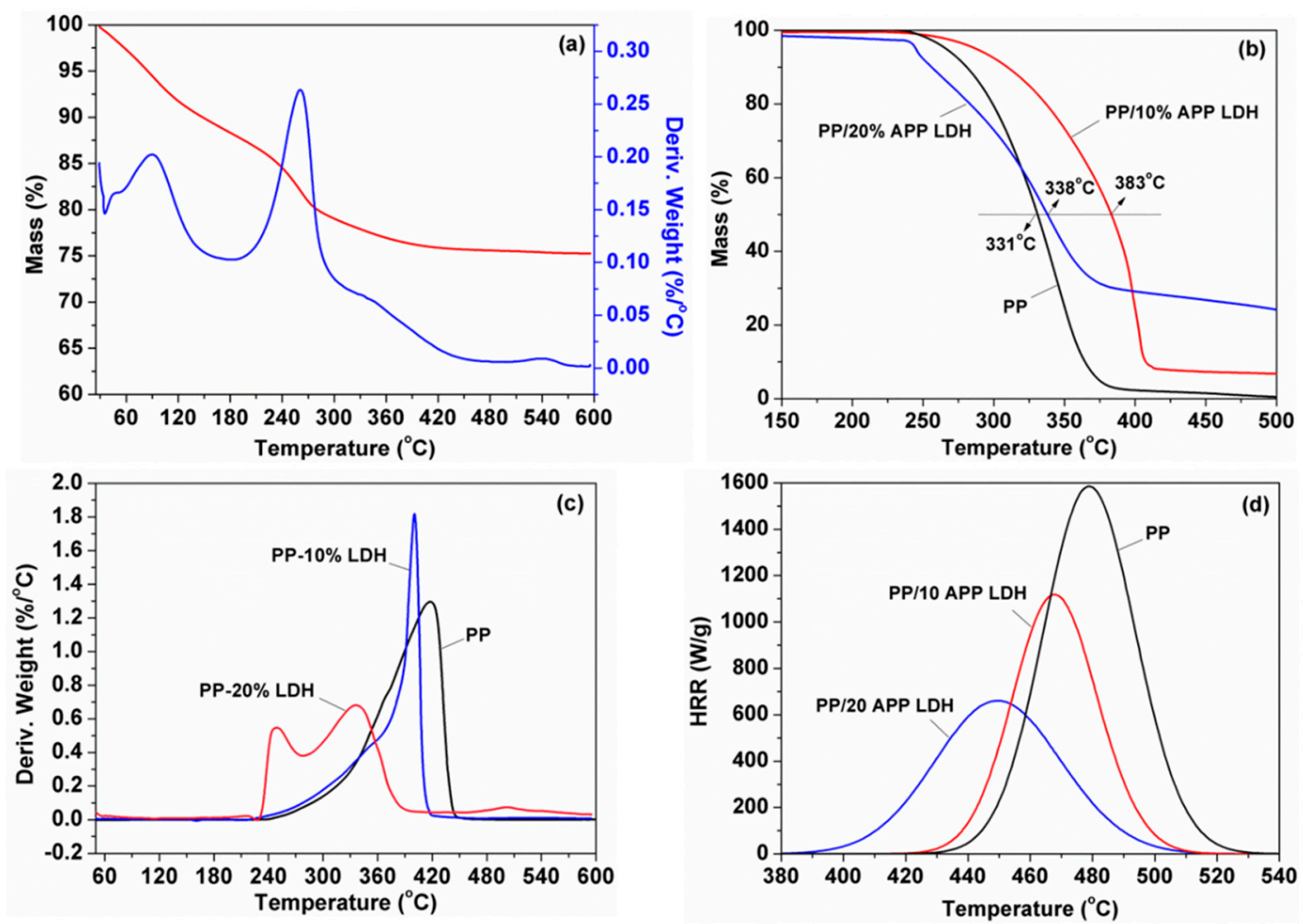

Figure 6. (a) Thermogravimetric-differential thermal gravity (TGA-DTG) curve of APP-LDH, (b) TGA, and (c) DTG curves of pure PP and PP/APP-LDH nanocomposites, and (d) microscale combustion calorimeter (MCC) analyses of pure PP and PP/APP-LDH nanocomposites. 
Table 1. Summary of TGA results for PP, PP/APP-LDH, and PP/APP-LDH/ZB nanocomposites ${ }^{a}$.

\begin{tabular}{|c|c|c|c|c|c|c|}
\hline Samples & $T_{10 \%}\left({ }^{\circ} \mathrm{C}\right)$ & $\Delta T_{10 \%}\left({ }^{\circ} \mathrm{C}\right)$ & $T_{50 \%}\left({ }^{\circ} \mathrm{C}\right)$ & $\Delta T_{50 \%}\left({ }^{\circ} \mathrm{C}\right)$ & $\begin{array}{c}\operatorname{Char}_{(\mathrm{E})} b \\
(\text { wt } \%)\end{array}$ & $\begin{array}{c}\operatorname{Char}_{(\mathrm{T})} b \\
(\mathrm{wt} \%)\end{array}$ \\
\hline PP & 280 & NA & 331 & NA & 0.7 & - \\
\hline PP/10\% APP-LDH & 310 & 30 & 383 & 52 & 7.0 & 6.8 \\
\hline $\mathrm{PP} / 20 \%$ APP-LDH & 257 & -23 & 336 & 7 & 24.1 & 15.6 \\
\hline PP $/ 10 \%$ APP LDH-2\% ZB & 308 & 28 & 367 & 36 & 12.0 & 9.6 \\
\hline PP $/ 10 \%$ APP LDH-4\% ZB & 288 & 8 & 367 & 36 & 15.4 & 11.1 \\
\hline PP $/ 10 \%$ APP LDH-6\% ZB & 281 & 1 & 362 & 31 & 17.6 & 12.6 \\
\hline PP /20\% APP LDH-2\% ZB & 255 & -25 & 341 & 10 & 26.3 & 17.1 \\
\hline PP $/ 20 \%$ APP LDH- $4 \%$ ZB & 267 & -13 & 358 & 27 & 28.3 & 18.5 \\
\hline PP /20\% APP LDH-6\% ZB & 259 & -21 & 360 & 29 & 27.4 & 20.0 \\
\hline
\end{tabular}

To confirm the function of the char forming, the theoretical char residue of PP/APP-LDH was calculated by linear combination, as shown in Table 1 [37]. The experimental and theoretical char yield for PP/20\% APP-LDH nanocomposites are 24.1 and $15.6 \mathrm{wt} \%$, respectively. It is obvious that the calculated char yield was much lower than the measured one, which further suggested that the addition of APP-LDH enhanced the char formation.

Figure $6 \mathrm{~d}$ displays the MCC results of PP and PP/APP-LDH nanocomposites. It can be observed that PP burned rapidly after ignition, for which the peak heat release rate (PHRR) value was $1585 \mathrm{kWm}^{-2}$. As expected, incorporating 10 or $20 \mathrm{wt} \%$ APP-LDH into PP significantly decreased the PHRR value to 1154 and $707 \mathrm{kWm}^{-2}$, respectively, for the which reduction was $27 \%$ and $55 \%$. Besides, both the total heat release (THR) and heat release capacity (HRC) values decreased significantly (Table 2).

Table 2. Summary of microscale combustion calorimeter (MCC) results for PP, PP/APP-LDH, and PP/APP-LDH/ZB nanocomposites ${ }^{a}$.

\begin{tabular}{cccccc}
\hline Samples & PHRR $\left(\mathbf{W g}^{-\mathbf{1}}\right)$ & Reduction (\%) & $\begin{array}{c}\text { THR } \\
\left(\mathbf{k J g}^{-\mathbf{1}}\right)\end{array}$ & $\begin{array}{c}\mathbf{T}_{\max } \\
\left({ }^{\circ} \mathbf{C}\right)\end{array}$ & $\begin{array}{c}\mathbf{H R C} \\
\left.\mathbf{( J g}^{-\mathbf{1}} \mathbf{K}^{-\mathbf{1}}\right)\end{array}$ \\
\hline PP & 1585 & NA & 47.6 & 479 & 1163 \\
PP/10\% CO $-\mathrm{LDH}$ & 1422 & 10 & 43 & 481.8 & 1071 \\
PP/20\% CO - -LDH & 1099 & 31 & 37.7 & 484.5 & 822 \\
PP/10\% APP LDH & 1154 & 27 & 42.5 & 468 & 1097 \\
PP/20\% APP LDH & 707 & 55 & 34.0 & 455 & 661 \\
PP/10\% APP LDH-2\% ZB & 918 & 42 & 40.3 & 460 & 869 \\
PP/10\% APP LDH-4\% ZB & 1047 & 34 & 40.0 & 463 & 990 \\
PP/10\% APP LDH-6\% ZB & 1167 & 26 & 37.3 & 459 & 880 \\
PP/20\% APP LDH-2\% ZB & 668 & 58 & 34.5 & 451 & 636 \\
PP/20\% APP LDH-4\% ZB & 790 & 50 & 35.0 & 458 & 750 \\
PP/20\% APP LDH-6\% ZB & 830 & 48 & 29.7 & 452 & 619 \\
\hline
\end{tabular}

${ }^{a} \mathrm{PHRR}=$ peak heat release rate; $\mathrm{THR}=$ total heat release; $T_{\max }=$ temperature at maximum pyrolysis rate; $\mathrm{HRC}=$ heat release capacity.

\section{Discussion}

In order to further increase the flame retardant properties of PP polymers, at the same time, to not affect the thermal stability of the composites caused by the high additives loading, ZB was added to PP/LDH systems and the thermal stability and flame retardant performance was studied systematically. Thermogravimetric analyzer (TGA) analyses for PP and PP/LDH/ZB composites are shown in Figure 7 and the corresponding results are listed in Table 1. After incorporation of $\mathrm{ZB}$ to PP/LDH systems, The $T_{50 \%}$ increased significantly when compared to pure PP, especially for $\mathrm{PP} / \mathrm{LDH} / \mathrm{ZB}$ composites with $10 \mathrm{wt} \% \mathrm{LDH}$. The increased value was slightly lower than PP/LDH 
composites without $\mathrm{ZB}\left(52{ }^{\circ} \mathrm{C}\right)$, but the value of $T_{50 \%}$ increased by at least $30^{\circ} \mathrm{C}$ no matter with 2,4 , or $6 \mathrm{wt} \% \mathrm{ZB}$ together. When the LDH loading increased to $20 \mathrm{wt} \% \mathrm{LDH}$, the $T_{0.5}$ of PP/LDH/ZB composites increased 10,27 , and $29^{\circ} \mathrm{C}$, respectively. Differential scanning calorimetry (DSC) analysis of pure PP and PP/LDH/ZB composites was studied as well. As shown in Figure S1, for pure PP, there is only one endothermic peak located at around $175^{\circ} \mathrm{C}$, corresponding to the melting points of PP polymer. After addition of $\mathrm{LDH} / \mathrm{ZB}$, another endothermic peak at around $225 \sim 233^{\circ} \mathrm{C}$ can be observed, which can be attributed to the existence of $\mathrm{LDH}$. The first degradation of $\mathrm{ZB}$ was around $170{ }^{\circ} \mathrm{C}$ according to TGA and DTG results, which was close to pure PP and the melting point of ZB was very high, laying above the upper temperature of the DSC experiment, so there were no more peaks for PP/LDH/ZB composites. In addition, the experimental char yield of PP/LDH/ZB composites was much higher than the theoretical one, indicating the $\mathrm{LDH} / \mathrm{ZB}$ additives promoted the formation of char during combustion. Moreover, it is worth emphasizing that after adding ZB to PP/LDH system, the experimental char yield also increased, suggesting the addition of $\mathrm{ZB}$ further accelerated the char residue.
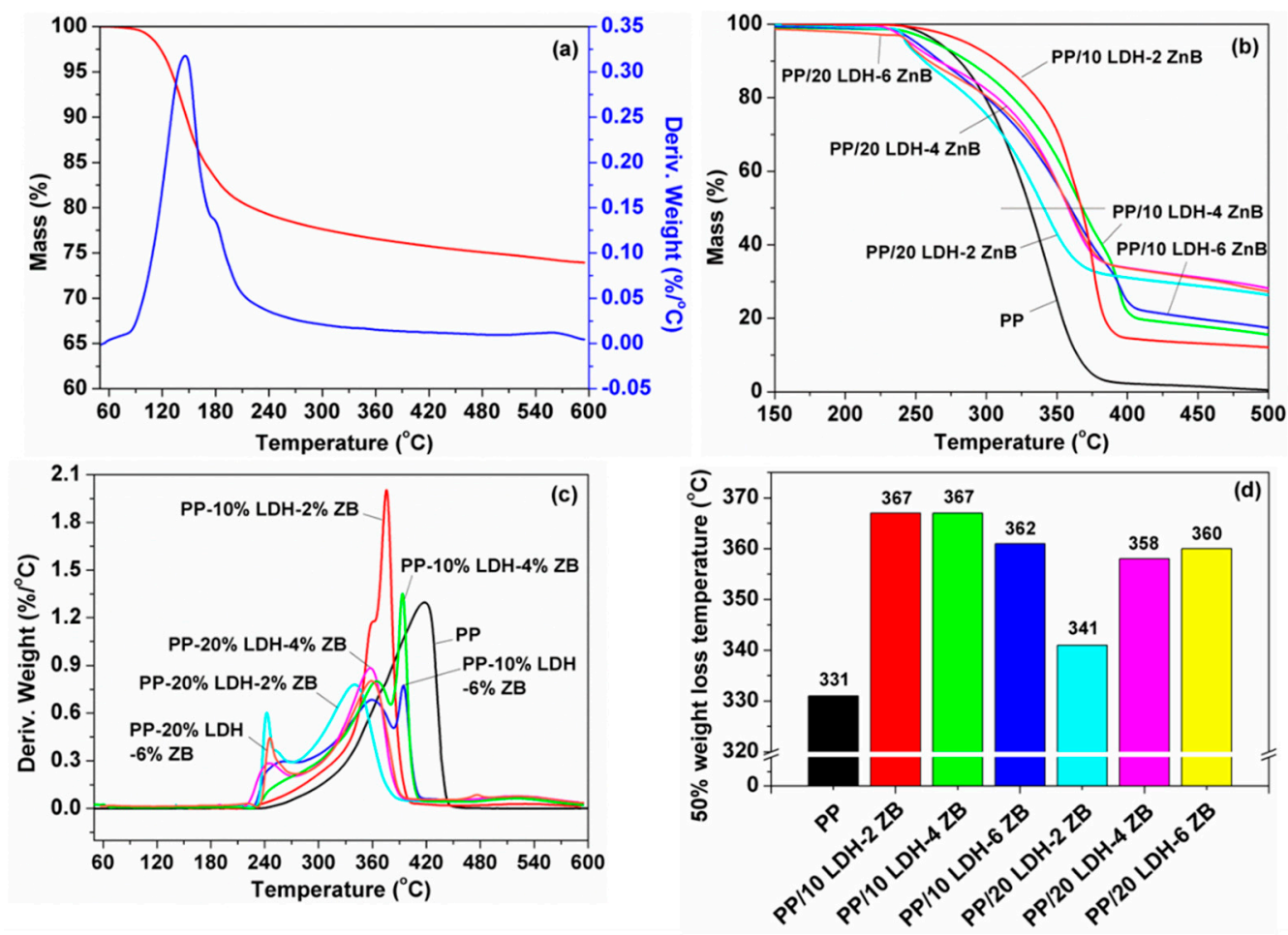

Figure 7. (a) Thermogravimetric-Differential thermal gravity (TGA-DTG) curve of ZB, (b) TGA and (c) DTG curves of pure PP and PP/APP-LDH/ZB nanocomposites, and (d) 50\% weight loss temperature of all the samples.

For the flammability properties, pure PP burnt easily with a high PHRR value of $1585 \mathrm{~W} \mathrm{~g}^{-1}$, after incorporation of $10 \mathrm{wt} \%$ and $20 \mathrm{wt} \%$ APP-LDH, and the PHRR value decreased by $27 \%$ and $55 \%$, respectively (Table 2), which was much higher than carbonate intercalated LDH. However, on the basis of this, the addition of ZB further increased the flame retardant factor of PP. Figure 8 represents the HRR curves of PP composites and the corresponding results are listed in Table 2 as well. When adding $2 \mathrm{wt} \% \mathrm{ZB}$, the PHRR value of PP/LDH/ZB composites with $10 \mathrm{wt} \% \mathrm{LDH}$ loading was $918 \mathrm{Wg}^{-1}$, which was reduced by $42 \%$ compared to pure PP, which decreased by $20 \%$ compared to the PP/LDH composites. However, when loading more ZB, such as 4 or $6 \mathrm{wt} \%$, the PHRR was slightly lower than $2 \mathrm{wt} \%$ loading. Therefore, it can be concluded that only $2 \mathrm{wt} \% \mathrm{ZB}$ could result in better flame retardant performance, and excessive $\mathrm{ZB}$ may decrease the flame retardancy. Similar results were obtained for the PP/LDH/ZB composites with $20 \mathrm{wt} \% \mathrm{LDH}$. The mechanism for ZB to improve the 
flame retardancy of polymer can be attributed to the glassy layer formed by it which can protect the inner polymer materials from further burning [38].
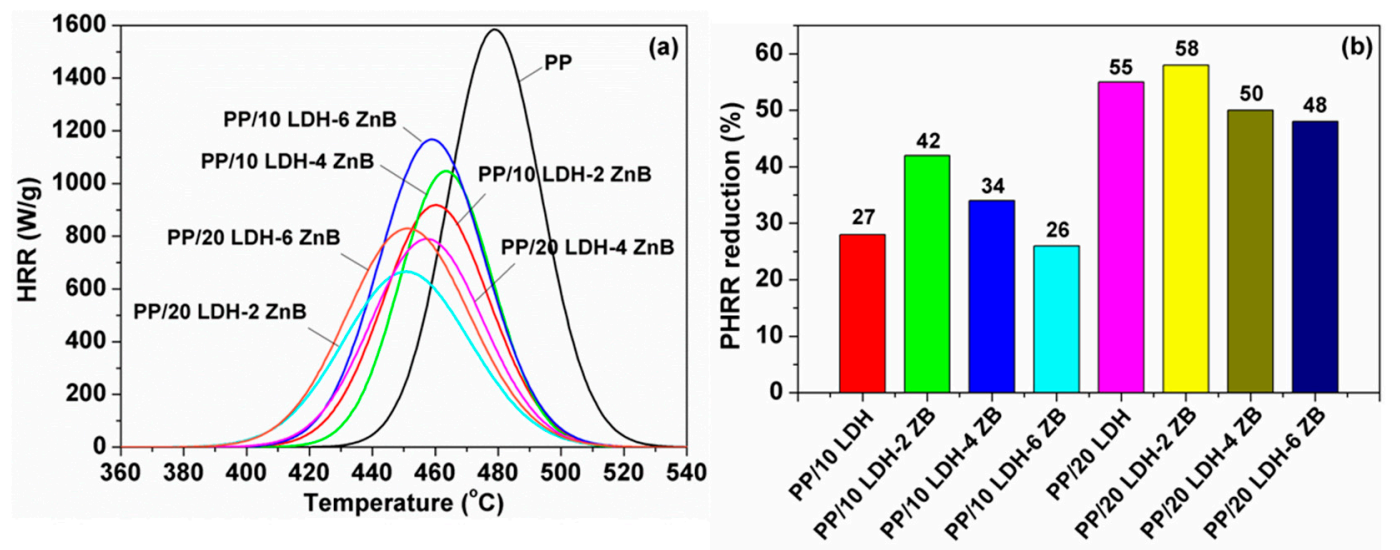

Figure 8. (a) HRR curves and (b) PHRR reduction of PP and PP/APP-LDH/ZB nanocomposites prepared.

In order to study the char residue morphologies of $\mathrm{PP} / \mathrm{LDH}$ and $\mathrm{PP} / \mathrm{LDH} / \mathrm{ZB}$ composites, SEM-EDS analyses of the residue char is showed in Figure 9. During combustion, APP in the LDH interlayers will work as a vigorous dehydrating agent, which can react with PP and decompose to form carbides, phosphorus oxides or phosphoric acid covering the surface of the composites (Figure 9a,c). On the one hand, it can prevent the inner PP from further thermal degradation as well as stop the combustibles produced by the degradation contacting to the surface of PP. On the other hand, the formed layer can block the contact of outside flammable gases such as oxygen with polymers, delaying the thermal decomposition and burning rate of the materials.

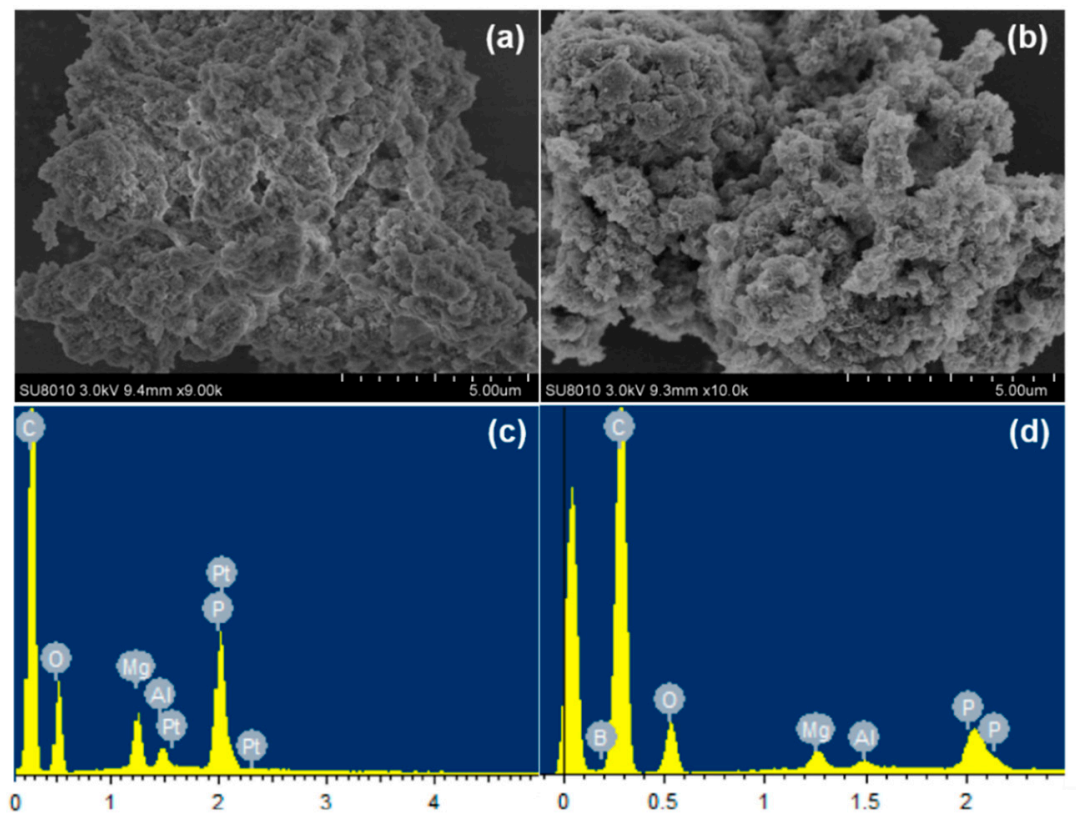

Figure 9. SEM-EDS images of (a,c) PP $/ 20 \mathrm{w}$ t $\%$ APP-LDHs and $(\mathbf{b}, \mathbf{d}) \mathrm{PP} / 20 \mathrm{wt} \%$ APP-LDHs $/ 2 \mathrm{wt} \%$ ZB composites char residue after combustion.

After incorporation of ZB to PP/APP-LDH composites, the carbon layer formed by thermal decomposition of APP can react with the glassy substance formed by ZB decomposition, which covers the surface of PP composites, making the char layer puffy and compact (Figure $9 \mathrm{~b}$ ). This is because ZB belongs to a low-melting vitreous humour, which will form a viscous substance when 
heated, and further seals the carbon layer formed by burning, blocking the heat exchange behavior between the material and the outside, thereby slowing the burning rate of the material. Moreover, the thermal stability of the carbon layer will be enhanced due to the presence of a zinc-containing compound, and thus reduce the decomposition rate of the materials greatly. From EDS analyses, except phosphorus, boron also can be observed in PP/APP-LDH/ZB composites, suggesting the existence of $Z B$. However, because of the very low loading of $Z B(2 \mathrm{wt} \%)$, zinc did not exist in the sample. In a word, it is believed that $\mathrm{ZB}$ combined with $\mathrm{LDH}$ can function as a synergistic additive to promote the formation of char residue to protect the polymers.

Since inorganic nanofillers can affect the mechanical properties, especially when the additives loading is high, the tensile strength (TS) and elongation at break (EB) was studied, and the results are shown in Figure 10. The TS and EB of pure PP was $34.8 \mathrm{MPa}$ and $33.1 \%$, respectively. After adding LDH nanofillers, both TS and EB decreased significantly. However, the mechanical properties of $\mathrm{PP} / \mathrm{LDH} / \mathrm{ZB}$ nanocomposites have not decreased very much while the flame retardant performance improved as expected. Therefore, the addition of $Z B$ is better in flame retardancy as well as in maintaining the mechanical properties of $\mathrm{PP} / \mathrm{LDH}$ nanocomposites.

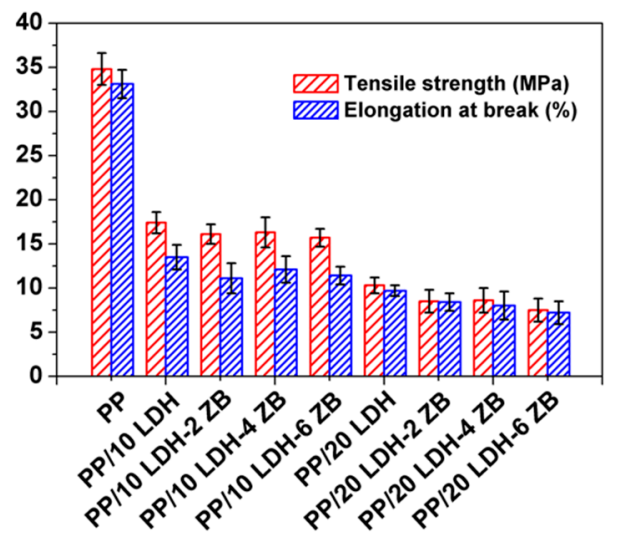

Figure 10. Mechanical properties of PP and PP/LDH nanocomposites.

\section{Conclusions}

In this contribution, the PP/APP-LDH and PP/APP-LDH/ZB nanocomposites were synthesized by solvent mixing method successfully. Both APP-LDH and ZB dispersed well within the PP matrix after aqueous miscible organic solvent treatment (AMOST). Microscale combustion calorimeter (MCC) and TGA results displayed that the APP-LDH had an outstanding flame retardant and thermal stability property for PP. With 10 and $20 \mathrm{wt} \%$ addition, the PHRR reduction reached to $27 \%$ and $55 \%$, and the $T_{50 \%}$ increased by $52{ }^{\circ} \mathrm{C}$ and $7{ }^{\circ} \mathrm{C}$, respectively. We also found that addition of a very small amount of ZB can enhance the flame retardancy and thermal stability further. This is because ZB can form a viscous substance and make the carbon layer more sealed. Therefore, it is a significant attempt to improve the flame retardant and thermal stability properties of PP by using halogen free additives.

Supplementary Materials: The following are available online at http:/ / www.mdpi.com/2073-4360/10/10/1114/ s1, Figure S1: DSC curves (exo up) of the pure PP and PP/LDH/ZB composites.

Author Contributions: Conceptualization, Q.W.; Methodology, Y.G. and Q.W.; Software, Y.G.; Validation, Y.G., Q.W. and W.L.; Formal Analysis, W.L.; Investigation, Y.G.; Resources, Q.W.; Data Curation, Y.G.; Writing-Original Draft Preparation, Y.G.; Writing-Review \& Editing, Q.W. and W.L.; Supervision, Q.W.; Project Administration, Q.W.; Funding Acquisition, Y.G. and Q.

Funding: This work was supported by the Beijing Natural Science Foundation (2184114), the National Natural Science Foundation of China (51622801, 51572029), the Beijing Excellent Young Scholar (2015000026833ZK11) and special guiding funds for the characteristic development and the building of world-class Universities (Disciplines) of Central Universities - Discipline of Landscape and Architecture of Beijing Forestry University.

Conflicts of Interest: The authors declare no conflict of interest. 


\section{References}

1. Wang, L.J.; He, X.J.; Lu, H.D.; Feng, J.X.; Xie, X.L.; Su, S.P.; Wilkie, C.A. Flame retardancy of polypropylene (nano)composites containing LDH and zinc borate. Polym. Adv. Technol. 2011, 22, 1131-1138. [CrossRef]

2. Lim, K.-S.; Bee, S.-T.; Sin, L.T.; Tee, T.-T.; Ratnam, C.T.; Hui, D.; Rahmat, A.R. A review of application of ammonium polyphosphate as intumescent flame retardant in thermoplastic composites. Compos. Part B Eng. 2016, 84, 155-174. [CrossRef]

3. Zhou, L.; Shao, M.F.; Wei, M.; Duan, X. Advances in efficient electrocatalysts based on layered double hydroxides and their derivatives. J. Energy Chem. 2017, 26, 1094-1106. [CrossRef]

4. Qin, Q.Q.; Wang, J.Y.; Zhou, T.T.; Zheng, Q.W.; Huang, L.; Zhang, Y.; Lu, P.; Umar, A.; Louis, B.; Wang, Q. Impact of organic interlayer anions on the $\mathrm{CO}_{2}$ adsorption performance of $\mathrm{Mg}$-Al layered double hydroxides derived mixed oxides. J. Energy Chem. 2017, 26, 346-353. [CrossRef]

5. Chu, X.Y.; Deng, T.; Zhang, W.; Wang, D.; Liu, X.F.; Zhang, C.; Qin, T.T.; Zhang, L.Y.; Zhang, B.S.; Chen, C.M.; et al. Architecture of Co-layered double hydroxide nanocages/graphene composite electrode with high electrochemical performance for supercapacitor. J. Energy Chem. 2018, 27, 507-512. [CrossRef]

6. Qiu, L.; Gao, Y.S.; Zhang, C.; Yan, Q.H.; O’Hare, D.; Wang, Q. Synthesis of highly efficient flame retardant polypropylene nanocomposites with surfactant intercalated layered double hydroxides. Dalton Trans. 2018, 47, 2965-2975. [CrossRef] [PubMed]

7. Guo, B.T.; Liu, Y.Z.; Zhang, Q.; Wang, F.Q.; Wang, Q.W.; Liu, Y.X.; Li, J.; Yu, H.P. Efficient flame-retardant and smoke-suppression properties of $\mathrm{Mg}$-Al-layered double-hydroxide nanostructures on wood substrate. ACS Appl. Mater. Interfaces 2017, 9, 23039-23047. [CrossRef] [PubMed]

8. Edenharter, A.; Feicht, P.; Diar-Bakerly, B.; Beyer, G.; Breu, J. Superior flame retardant by combining high aspect ratio layered double hydroxide and graphene oxide. Polymer 2016, 91, 41-49. [CrossRef]

9. Gao, Y.S.; Wang, Q.; Wang, J.Y.; Huang, L.; Yan, X.R.; Zhang, X.; He, Q.L.; Xing, Z.P.; Guo, Z.H. Synthesis of highly efficient flame retardant HDPE nanocomposites with inorgano-LDH as nanofiller using solvent mixing method. ACS Appl. Mater. Interfaces 2014, 6, 5094-5104. [CrossRef] [PubMed]

10. Ling, S.; Li, D.Q.; Li, S.F.; Wang, J.R.; Evans, D.G.; Duan, X. Structure, flame retarding and smoke suppressing properties of $\mathrm{Zn}-\mathrm{Mg}-\mathrm{Al}-\mathrm{CO}_{3}$ layered double hydroxides. Chin. Sci. Bull. 2005, 50, 1101-1104.

11. Shao, Z.B.; Deng, C.; Tan, Y.; Chen, M.J.; Chen, L.; Wang, Y.Z. An efficient mono-component polymeric intumescent flame retardant for polypropylene: preparation and application. ACS Appl. Mater. Interfaces 2014, 6, 7363-7370. [CrossRef] [PubMed]

12. Zhang, G.B.; Ding, P.; Zhang, M.; Qu, B.J. Synergistic effects of layered double hydroxide with hyperfine magnesium hydroxide in halogen-free flame retardant EVA/HFMH/LDH nanocomposites. Polym. Degrad. Stab. 2007, 92, 1715-1720. [CrossRef]

13. Levchik, S.V.; Weil, E.D. A review of recent progress in phosphorus-based flame retardant. J. Fire Sci. 2006, 24, 345-364. [CrossRef]

14. Zhao, C.X.; Liu, Y.; Wang, D.Y.; Wang, D.L.; Wang, Y.Z. Synergistic effect of ammonium poluphosphate and layered double hydroxide on flame retardant properties of poly(vinyl alcohol). Polym. Degrad. Stab. 2008, 93, 1323-1331. [CrossRef]

15. Wang, X.; Zhou, S.; Xing, W.Y.; Yu, B.; Feng, X.M.; Song, L.; Hu, Y. Self-assembly of Ni-Fe layered double hydroxide/graphene hybrids for reducing fire hazard in epoxy composites. J. Mater. Chem. A 2013, 1, 4383-4390. [CrossRef]

16. Qian, Y.; Zhou, S.J.; Chen, X.L. Flammability and thermal degradation behavior of ethylene-vinyl acetate/layered double hydroxides/zinc borate composites. Polym. Adv. Technol. 2017, 28, 353-361. [CrossRef]

17. Li, Z.; Zhang, J.H.; Dufosse, F.; Wang, D.Y. Ultrafine nickel nanocatalyst-engineering of an organic layered double hydroxide towards a super-efficient fire-safe epoxy resin via interfacial catalysis. J. Mater. Chem. A 2018, 6, 8488-8498. [CrossRef]

18. Wang, X.; Spörer, Y.; Leuteritz, A.; Kuehnert, I.; Wagenknecht, U.; Heinrich, G.; Wang, D.Y. Comparative study of the synergistic effect of binary and ternary LDH with intumescent flame retardant on the properties of polypropylene composites. RSC Adv. 2015, 5, 78979-78985. [CrossRef]

19. Zhao, C.X.; Peng, G.; Liu, B.L.; Jiang, Z.W. Synergistic effect of organically modified layered double hydroxide on thermal and flame-retardant properties of poly(butyl acrylate-vinyl acetate). J. Polym. Res. 2011, 18, 1971-1981. [CrossRef] 
20. Lewin, M. Synergistic and catalytic effects in flame retardancy of polymeric materials-An overview. J. Fire Sci. 1999, 17, 3-19. [CrossRef]

21. Li, L.; Qian, Y.; Jiao, C.M. Synergistic flame retardant effects of ammonium polyphosphate in ethylene-vinyl acetate/layered double hydroxides composites. Polym. Eng. Sci. 2014, 54, 766-776. [CrossRef]

22. Nyambo, C.; Kandare, E.; Wang, D.Y.; Wilkie, C.A. Flame-retarded polystyrene: Investigating chemical interactions between ammonium polyphosphate and MgAl layered double hydroxide. Polym. Degrad. Stab. 2008, 93, 1656-1663. [CrossRef]

23. Kalali, E.N.; Montes, A.; Wang, X.; Zhang, L.; Shabestari, M.J.; Li, Z.; Wang, D.Y. Effect of phytic acid-modified layered double hydroxide on flammability and mechanical properties of intumescent flame retardant polypropylene system. Fire Mater. 2018, 42, 213-220. [CrossRef]

24. Schubert, D.M.; Alam, F.; Visi, M.Z.; Knobler, C.B. Structural characterization and chemistry of the industrially important zinc borate $\mathrm{Zn}\left[\mathrm{B}_{3} \mathrm{O}_{4}(\mathrm{OH})_{3}\right.$ ]. Chem. Mater. 2003, 15, 866-871. [CrossRef]

25. Wu, X.F.; Wang, L.C.; Wu, C.; Wang, G.L.; Jiang, P.K. Flammability of EVA/IFR (APP/PER/ZB system) and EVA/IFR/synergist $\left(\mathrm{CaCO}_{3}, \mathrm{NG}\right.$, and EG) composites. J. Appl. Polym. Sci. 2012, 126, 1917-1928. [CrossRef]

26. Bourbigot, S.; Bras, M.L.; Leeuwendal, R.; Shen, K.K.; Schubert, D. Recent advances in the use of zinc borates in flame retardancy of EVA. Polym. Degrad. Stab. 1999, 64, 419-425. [CrossRef]

27. Shi, X.X.; Xiao, Y.; Li, M.; Yuan, L.J.; Sun, J.T. Synthesis of an industrially important zinc borate $2 \mathrm{ZnO} \cdot 3 \mathrm{~B}_{2} \mathrm{O}_{3} \cdot 3 \mathrm{H}_{2} \mathrm{O}$ by a rheological phase reaction method. Powder Technol. 2008, 186, 263-266. [CrossRef]

28. Gao, Y.S.; Zhang, Y.; Williams, G.R.; O'are, D.; Wang, Q. Layered double hydroxide-oxidized carbon nanotube hybrids as highly efficient flame retardant nanofillers for polypropylene. Sci. Rep. 2016, 6, 35502. [CrossRef] [PubMed]

29. Li, Z.C.; Xue, Z.H.; Yang, B.J.; Wang, B.N.; Peng, X.H. One-pot In Situ Synthesis of hollow layered double hydroxide ammonium polyphosphate nanoshells toward flame retardant. Chem. Lett. 2014, 43, 1879-1881. [CrossRef]

30. Occelli, M.L.; Olivier, J.P.; Auroux, A.; Kalwei, M.; Eckert, H. Basicity and Porosity of a Calcined Hydrotalcite-Type Material from Nitrogen Porosimetry and Adsorption Microcalorimetry Methods. Chem. Mater. 2003, 15, 4231-4238. [CrossRef]

31. Gao, Y.S.; Wang, Q.; Qiu, L.; Wu, J.W.; Yan, X.R.; Umar, A.; Guo, J.; Zhang, X.; Wang, J.Y.; Guo, Z.H. Ethylene-vinyl acetate/LDH nanocomposites with enhanced thermal stability, flame retardancy, and rheological property. Polym. Compos. 2016, 37, 3449-3459. [CrossRef]

32. Gao, Y.H.; Liu, Z.H. Synthesis and thermochemistry of two zinc borates, $\mathrm{Zn}_{2} \mathrm{~B}_{6} \mathrm{O}_{11} \cdot 7 \mathrm{H}_{2} \mathrm{O}$ and $\mathrm{Zn}_{3} \mathrm{~B}_{10} \mathrm{O}_{18} \cdot 14 \mathrm{H}_{2} \mathrm{O}$. Thermochim. Acta 2009, 484, 27-31. [CrossRef]

33. Li, J.; Xia, S.P.; Gao, S.Y. FT-IR and Raman spectroscopic study of hydrated borates. Spectrochim. Acta 1995, 51, 519-532. [CrossRef]

34. Guo, Y.W.; Mao, L.; Rong, F.; Liu, Z.H. Preparation of $\mathrm{Zn}_{3} \mathrm{~B}_{10} \mathrm{O}_{18} \cdot 14 \mathrm{H}_{2} \mathrm{O}$ nanomaterials and their thermochemical properties. Thermochim. Acta 2012, 539, 56-61. [CrossRef]

35. Patra, N.; Salerno, M.; Cozzoli, P.D.; Athanassiou, A. Surfactant-induced thermomechanical and morphological changes in TiO2-polystyrene nanocomposites. J. Colloid Interface Sci. 2013, 405, 103-108. [CrossRef] [PubMed]

36. Patra, N.; Salerno, M.; Cozzoli, P.D.; Barone, A.C.; Ceseracciu, L.; Pignatelli, F.; Carzino, R.; Marini, L.; Athanassiou, A. Thermal and mechanical characterization of poly(methyl methacrylate) nanocomposites filled with $\mathrm{TiO}_{2}$ nanorods. Compos. Part B Eng. 2012, 43, 3114-3119. [CrossRef]

37. Giraud, S.; Bourbigot, S.; Rochery, M.; Vroman, I.; Tighzert, L.; Delobel, R. Microencapsulation of phosphate: application to flame retarded coated cotton. Polym. Degrad. Stab. 2002, 77, 285-297. [CrossRef]

38. Li, Y.M.; Deng, C.; Long, J.W.; Huang, S.C.; Zhao, Z.Y.; Wang, Y.Z. Improving fire retardancy of ceramifiable polyolefin system via a hybrid of zinc borate@melamine cyanurate. Polym. Degrad. Stab. 2018, 153, 325-332. [CrossRef]

(C) 2018 by the authors. Licensee MDPI, Basel, Switzerland. This article is an open access article distributed under the terms and conditions of the Creative Commons Attribution (CC BY) license (http:/ / creativecommons.org/licenses/by/4.0/). 